\title{
Interplay between endocrinology, metabolism and COVID-19 infection
}

\author{
Authors: Sai Man Mung ${ }^{A}$ and Edward B Jude ${ }^{B}$
}

There are more than $\mathbf{1 7 0}$ million confirmed cases of COVID-19 worldwide, yet its effects on the endocrine system remain under-reported due to lack of awareness by the public, primary care givers and specialists. This is a narrative review using up-to-date literature discussing the consequences that infection with SARS-CoV-2 can have on diabetes and the endocrine glands including the adrenals, thyroid and pituitary, as well as hyponatremia and hypogonadism. Endocrinologists, internists and primary care physicians need to be aware of the involvement of the endocrine organs when dealing with people recovering from COVID-19 and actively manage any complications to reduce mortality and improve the quality of life of those affected.

KEYWORDS: COVID-19, SARS-CoV-2, endocrinology, metabolism, diabetes, pituitary, thyroid, adrenal, testes, pancreas, hyponatraemia

DOI: 10.7861/clinmed.2021-0200

\section{Introduction}

SARS-CoV-2 is a coronavirus that causes COVID-19 and was first reported in December 2019 in China. In March 2020, the World Health Organization (WHO) declared it a global pandemic. As of 5 May 2021, there have been 153,738,171 confirmed cases of COVID-19 globally, with 3,217,281 deaths. ${ }^{1}$ In the UK, the numbers have been staggering, with over 4.4 million people contracting the disease and more than 151,000 fatalities. ${ }^{2}$ Acute respiratory failure and sepsis are the main causes of death in COVID-19.

Like the alveolar epithelial cells found in the lungs, which express ACE2 receptors, endocrine organs also express this receptor. ${ }^{3-6}$ ACE2 receptors facilitate SARS-CoV-2 attachment and therefore entry into the cell. The virus then induces cell damage via release

Authors: ${ }^{A}$ specialist registrar in diabetes and endocrinology, Tameside and Glossop Integrated Care NHS Foundation Trust, Manchester, UK; ${ }^{\mathrm{B}}$ consultant diabetologist and endocrinologist, Tameside and Glossop Integrated Care NHS Foundation Trust, Manchester, UK, honorary professor, University of Manchester, Manchester, UK, and honorary professor, Manchester Metropolitan University, Manchester, UK of proinflammatory cytokines such as TNF-alpha, IFN-gamma, IL6 and acute phase reactants like ferritin, CRP and D-dimer. ${ }^{7}$

It is possible that the effects of SARS-CoV-2 on the endocrine system is underreported due to lack of awareness by the public, primary care givers and specialists, and we are still learning about the damaging effects of the virus on the endocrine organs.

This article is a narrative review of the literature available, up to early 2021, about the interplay between SARS-CoV-2 and the endocrine system. The authors would like to point out that this is a rapidly moving field with new evidence constantly emerging.

\section{Evidence used in this review}

We conducted a search in MEDLINE using search terms 'endocrine,' 'pituitary,' 'thyroid,' 'adrenal,' 'testes,' 'diabetes,' 'pancreas,' 'hyponatraemia,' 'COVID-19' and 'SARS-CoV-2' to identify studies published from 2019 to 2021 . We identified systematic reviews, basic science publications, endocrine society guidelines, case reports and autopsy-based histopathological analysis published in English.

\section{Hyperglycaemia and diabetes \\ Aetiology}

The link between diabetes and SARS-CoV-2 is bidirectional. SARSCoV-2 can cause pancreatic damage through cytokine storm in the pancreas resulting in pancreatic endocrine and exocrine damage. The latter was demonstrated in a study on 67 patients with severe COVID-19, with higher levels of amylase observed in those with severe COVID-19 compared to mild cases. ${ }^{5}$

In a 'catch-22' situation, hyperglycaemia potentially exacerbates the cytokine storm seen in individuals with COVID-19. COVID-19 patients with diabetes had higher IL6, C-reactive protein and D-dimer levels than COVID-19 patients without diabetes. ${ }^{8,9}$

\section{Data from the COVID-19 population}

COVID-19-related mortality varied depending on the type of diabetes and the overall $\mathrm{HbA1c}$. Adjusted for risk factors including cerebrovascular disease and age, the odds ratio for hospital COVID-19-related death was 2.86 for type 1 diabetes and 1.80 for type 2 diabetes. ${ }^{10}$ Based on a population-based cohort study of people diagnosed with diabetes in England, compared with people with an $\mathrm{HbA} 1 \mathrm{c}$ of 48 to $53 \mathrm{mmol} / \mathrm{mol}$ (6.5-7.0\%), people with an $\mathrm{HbA} 1 \mathrm{c}$ of $86 \mathrm{mmol} / \mathrm{mol}(10.0 \%)$ or greater had higher 
COVID-19-related mortality (hazard ratio (HR) of 2.23 and 1.61 for type 1 and type 2 diabetes, respectively). ${ }^{11}$

COVID-19 poses a unique set of challenges for clinicians as it may precipitate newly diagnosed diabetes and associated complications as a result of endocrine failure due to progressive destruction of the pancreas. In patients hospitalised for COVID-19, 2.8\% were found to have newly diagnosed diabetes. ${ }^{12}$ In contrast, a systematic review of 110 patients with COVID-19 showed that $10 \%$ had newly diagnosed diabetes mellitus. In this cohort, it also showed that the mortality rate of mixed diabetic ketoacidosis (DKA) and hyperglycaemic hyperosmolar state (HHS) group was higher than the DKA only group. ${ }^{13}$ Consequently, all patients admitted with COVID-19 should be assessed for diabetes with a random blood glucose on admission and an $\mathrm{HbA} 1 \mathrm{c}$.

\section{Management}

Dexamethasone $6 \mathrm{mg}$ for 10 days is recommended in COVID-19 patients who require oxygen therapy and has been shown to reduce mortality rate by up to a third. ${ }^{14}$ However, such therapy can exacerbate the pre-existing insulin resistance that occurs in COVID-19 and can potentially precipitate hyperglycaemia, DKA and HHS. Even after cessation of steroid therapy, it may be several days before insulin resistance falls.

Consequently, optimal glucose control has been advocated in inpatients in multiple international diabetes guidelines, with a target blood glucose less than 10 to $12 \mathrm{mmol} / \mathrm{L}$ and to consider variable rate insulin and/or intermediate acting insulin if target glucose levels are not met. ${ }^{15,16}$ Not uncommonly, large doses of insulin may be required (1-2 units/kg) during acute admission, even in those who were previously insulin naive. International guidelines also stressed the need to highlight sick-day rules in a person with diabetes through education on symptoms of high glucose and encouraging them to check their blood glucose and ketones more frequently when unwell. ${ }^{17,18}$ They must never stop their insulin and should have an ample supply of their regular medications and equipment for glucose/ketone monitoring.

Treatment for diabetes and hypertension have been discussed extensively in this pandemic, given that pioglitazone, angiotensin-converting enzyme inhibitors (ACEI) and angiotensin receptor blockers (ARBs) all boost expression of ACE2 levels, and are thought to possibly increase the risk of SARS-CoV-2 viraemia. However, to date, there have been no reports of higher mortality or morbidity in those treated with these drugs and current guidance suggests continuing with these medications. ${ }^{19,20}$ However, metformin, sodium-glucose co-transporter 2 (SGLT2) inhibitors and glucagon-like peptide-1 (GLP-1) receptor agonists may need to be stopped during illness as it can potentiate dehydration and increase the risk of lactic acidosis and DKA. ${ }^{21,22}$

In vitro studies demonstrated immunosuppressive effects of dipeptidyl peptidase-IV (DPP-IV) inhibitors and have been suggested as a potential target in reducing the cytokine storm in COVID-19. ${ }^{23}$ A UK observational cohort study looking at type 2 diabetes and COVID-19-related mortality found a non-significant increase of COVID-19-related mortality in those prescribed with DPP-IV inhibitors (HR 1.07); however, this was confounded by the fact that this medication tends to be prescribed in older frailer population. $^{24}$

\section{Adrenal insufficiency}

Aetiology

Adrenal insufficiency may be one of the manifestations of COVID-19. The mechanism is thought to be due to the hypercoagulable state of the infection that causes acute adrenal infarction.

Adrenal insufficiency and COVID-19 have a bidirectional effect on each other as patients with adrenal insufficiency are also at a higher risk of infection. This may be explained by reduced cortisol secretion in adrenal insufficiency. Cortisol mediates the immune system through upregulating cytokines secreted by T helper 2 (TH2) cells, cells that produce antibodies against pathogens. ${ }^{25}$ Although not COVID-19 related, based on a retrospective cohort study of 1,580 patients in the UK, patients with adrenal insufficiency were at least twice to develop lower respiratory tract infection.

\section{Data from the COVID-19 population}

Adrenal infarction was radiologically evident in at least one in five patients based on a retrospective study of 219 patients with critical and severe COVID-19 symptoms undergoing chest $\mathrm{CT}^{26}$ Another mechanism that may cause adrenal insufficiency is adrenocortical haemorrhage and necrosis, as demonstrated in two post-mortem case series in patients with severe fatal COVID-19. ${ }^{27,28}$ However, with adequate patient education and management, patients with adrenal insufficiency are not at an increased risk of developing severe COVID-19 compared to controls. $^{29}$

\section{Management}

Much of what we know about managing COVID-19 in patients with adrenal insufficiency is guided by the Italian Society of Endocrinology and European Society of Endocrinology and is based on studies of critical illnesses. ${ }^{30,31}$ All patients with adrenal insufficiency must be informed about sick-day rules and double their steroid doses when they are unwell. In those with clinical signs of adrenal insufficiency and COVID-19, an oral stress dose cover with $20 \mathrm{mg}$ immediate-release hydrocortisone every 6 hours may be required, with a switch from modified release to immediate release advocated. ${ }^{31}$ The usual dose of fludrocortisone should be continued. Patients should be provided with a rescue pack (comprising of hydrocortisone $100 \mathrm{mg}$ ampoule, syringe and needles) and taught how to administer the hydrocortisone intramuscularly themselves (or by a carer/spouse) if they are unwell and unable to take oral hydrocortisone.

Although not specifically for COVID-19, hydrocortisone infusion is preferred over intermittent bolus administration in the treatment of adrenal crisis for its avoidance of frequent troughs and steady maintenance of cortisol as demonstrated in an integrated data analysis of cross-sectional, observational and pharmacokinetic studies of 410 patients. ${ }^{32}$

\section{Thyroid dysfunction}

\section{Aetiology}

An exaggerated immune response to the virus and direct viral infection of the gland has been postulated to be the mechanism 
of subacute thyroiditis in COVID-19. ${ }^{33}$ The natural course of this disease typically involves an initial thyrotoxic hyperthyroid phase followed by hypothyroid phase with subsequent recovery to a euthyroid state or that of hypothyroidism. Another mechanism of thyroid pathology is non-thyroidal illness (NTI) syndrome, characterised by low or normal plasma T4 in the presence of normal or slightly decreased thyroid-stimulating hormone (TSH).

\section{Data from the COVID-19 population}

While the majority of patients with COVID-19 are euthyroid, $13.1 \%$ of inpatients with the condition were found to have an abnormal thyroid test. ${ }^{33}$ As aforementioned, thyroid pathology in COVID-19 includes subacute thyroiditis, hypothyroidism, thyrotoxicosis and NTI. In a case series of eight patients with subacute thyroiditis, all but one were female, with the majority presenting weeks later with neck pain after their initial presentation of COVID-19 rather than early in admission. ${ }^{34}$

Hypothyroidism was present in $5.2 \%$ of 287 hospitalised COVID-19 non-intensive care unit (ICU) patients in a single-centre retrospective study, with the majority of them being subclinical rather than overtly hypothyroid. ${ }^{35}$ The same study found $20.2 \%$ of patients with thyrotoxicosis; however, the study was not designed to clarify the mechanism of its causation. Furthermore, dexamethasone therapy used in hypoxic COVID-19 patients may cause TSH suppression which may result in the erroneous diagnosis of hyperthyroidism, when this is not taken into account.

Primary hypothyroidism must be differentiated from NTI, which was evidenced by lower admission TSH and free T4 in those with COVID-19 compared to those without in a cohort observational study of 456 inpatients in the UK. ${ }^{36}$ In addition to lower TSH values, lower free T3 values correlated with the severity of COVID-19 in a retrospective study of 50 inpatient COVID-19 patients in China. ${ }^{37}$

\section{Management}

In most patients with thyroiditis, a wait and see approach is sufficient as the disease, frequently after a hypothyroid phase, resolves. In case reports of COVID-19 thyroiditis, steroids and non-specific beta blockers have been used to manage the initial hyperthyroid state and can be considered in patients with marked symptomatic disease. ${ }^{38,39}$ When hypothyroidism is confirmed, especially when symptomatic and TSH is $>10 \mathrm{mIU} / \mathrm{mL}$, levothyroxine therapy should be commenced.

To avoid the overdiagnosis of NTI, the authors suggest testing thyroid function only if there are symptoms to suggest hypothyroidism (such as fatigue) or hyperthyroidism (such as palpitations). If this is abnormal, it should be repeated in 3-6 months' time, as thyroid function tends to normalise at follow-up in inpatient survivors of COVID-19. ${ }^{36}$

\section{Pituitary apoplexy}

\section{Aetiology}

Through expression of ACE2 receptors in the pituitary gland, haematogenous spread and direct viral invasion of the olfactory nerve are thought to be the main modes of involvement of the pituitary gland. ${ }^{40}$ Gene sequencing of the virus had also previously been identified in the cerebrospinal fluid. ${ }^{41}$ Direct viral invasion of the olfactory nerve is implicated as half of COVID-19 patients have complete or partial loss of sense of smell (anosmia). ${ }^{42}$ Anosmia is also recognised as one of the earliest signs of COVID-19 infection. ${ }^{43}$

Haematological complications from SARS-CoV-2 including coagulopathy and thrombocytopaenia may contribute to the haemorrhagic picture of pituitary apoplexy and subsequent hypoadrenalism. ${ }^{44}$ Secondary adrenal insufficiency occurs in approximately two-thirds of patients with pituitary apoplexy and is an important correctable cause of mortality. ${ }^{45}$

\section{Data from COVID-19 population}

Pituitary apoplexy can present with a thunderclap headache, nausea, vomiting and cranial nerve palsy. There are at least three cases reported in the literature of pituitary apoplexy in the presence of macroadenoma and COVID-19, of which one of the patients had low morning cortisol. ${ }^{46-48}$ There was one case study of a pregnant female presenting with pituitary apoplexy and asymptomatic SARS-CoV-2 infection..$^{49}$ Further reports may help determine if there is a causal relationship or if these events are unrelated, such as an incidental finding of SARS-CoV-2 in a patient with critical illness.

\section{Management}

Pituitary apoplexy should be on the differential in persons presenting with thunderclap headache. A full workup should include pituitary profile testing and imaging. Prompt intravenous corticosteroid replacement should be commenced if there is any doubt of hypocortisolism such as haemodynamic instability.

All patients with suspected pituitary apoplexy should undergo SARS-CoV-2 PCR screening during this pandemic. The European Society of Endocrinology and the Pituitary Society produced guidance for the management of pituitary disease during this time. It recommends that patients with suspected pituitary apoplexy should have urgent brain CT to facilitate differential diagnosis. They should also continue to be operated on in an emergent fashion where indication for surgery is present, such as reduced consciousness level or reduced visual acuity. ${ }^{50,51}$

\section{Hyponatraemia}

\section{Aetiology}

Hyponatraemia occurs in nearly a third of patients with COVID-19. The cause of hyponatraemia in COVID-19 may be multifactorial. ${ }^{52}$ Proinflammatory cytokines such as IL6 stimulate antidiuretic hormone release causing syndrome of inappropriate antidiuretic hormone secretion (SIADH). Another mechanism is hypovolemic hyponatremia as a result of diarrhoea, vomiting and reduced oral intake. SIADH and hypovolaemia accounted equally to the cause of hyponatraemia in a retrospective, multicentre, observational cohort study in patients with COVID-19 across four hospitals in the USA. $^{53}$

\section{Data from COVID-19 population}

Hyponatraemia is an independent predictor of severity of COVID-19 including mortality and need for mechanical 
ventilation. ${ }^{54}$ The link between plasma sodium and mortality from COVID-19 is U-shaped. A retrospective study of patients with confirmed or highly suspected SARS-CoV-2 across seven countries revealed both hyponatremia and hypernatremia to be associated with higher mortality but only hyponatraemia was associated with admission to the ICU. ${ }^{53}$ This was likely due to patients with hypernatremia being older with more comorbidities, and therefore, less likely to be admitted to ICU.

\section{Management}

Patients with hyponatraemia should continue to be treated according to well-established guidelines. ${ }^{55}$ Fluid restriction is the mainstay of treatment in COVID-19-associated SIADH. In a case series of COVID-19 associated SIADH, fluid restriction between $750 \mathrm{~mL}$ and 1,200 mL daily improved the plasma sodium levels. ${ }^{56}$ As with non-COVID-19 individuals, infusion of hypertonic saline should be considered in the treatment of acute symptomatic hyponatraemia presenting with seizures and decreased consciousness level. In a case study of SARS-CoV-2-induced SIADH manifesting as acute severe hyponatraemia, fluid restriction and hypertonic saline infusion normalised the plasma sodium levels by day 4 of hospitalisation. ${ }^{57}$

The authors suggest checking serum and urine osmolality, urine sodium, thyroid function test and morning cortisol in patients with unexplained moderate to severe hyponatraemia. A thorough history including concomitant medications and volume assessment of the hyponatraemic patient is important to differentiate between the dehydrated patient who would warrant fluid replacement and the euvolaemic patient with SIADH who would warrant fluid restriction.

\section{Hypogonadism}

\section{Aetiology}

Like all other endocrine organs, the testes are also susceptible to SARS-CoV-2 viraemia. In a cohort study involving 38 patients,
SARS-CoV-2 was identified in the semen of those acutely infected and during convalescence. ${ }^{58}$ However, another study failed to demonstrate the presence of the virus in the semen of a COVID-19 patient cohort. ${ }^{59}$ To date, there have been no studies to demonstrate COVID-19 effects on the female reproductive system. However, ACE2 is also expressed in the ovaries and endometrium. ${ }^{60,61}$

\section{Data from the COVID-19 population}

Gonadal failure may manifest due to primary failure and, perhaps more commonly, secondary failure due to critical illness. Primary gonadal failure as a result of Leydig cell dysfunction and orchitis has been demonstrated in a case report. ${ }^{62}$ Lower testosterone levels were found in patients with COVID-19 managed on the ICU compared to those on a general medical ward in a series of 31 patients affected by SARS-CoV-2, suggesting that the low testosterone levels may be secondary to hypogonadotropic hypogonadism driven as a result of critical illness. ${ }^{63}$ Aside from lower testosterone levels, impaired sperm quality and quantity were also found in moderately affected individuals with COVID-19 in a cohort study of 34 men. ${ }^{64}$ These studies collectively suggest that SARS-CoV-2 may have an impact on fertility during the illness.

The drawbacks to the majority of these studies, however, are the low number of sampled patients and the absence of sperm analysis in individuals before infection and after recovery.

\section{Management}

More studies are required to ascertain the possible long-term effects on the reproductive system as impaired spermatogenesis can persist after an insult for up to 3 months. ${ }^{65}$

At present, the authors recommend checking early morning testosterone levels in all patients presenting with signs of hypogonadism such as reduced libido in 3-and 6-months' time after the primary infection (Table 1).

Table 1. Endocrine dysfunctions described in COVID-19 and authors' suggestions for patients and clinicians

\begin{tabular}{|c|c|c|c|c|c|c|}
\hline & Gonad & Pancreas & Adrenal & Thyroid & Pituitary & Hyponatraemia \\
\hline $\begin{array}{l}\text { Cases } \\
\text { described in } \\
\text { COVID-19 }\end{array}$ & $\begin{array}{l}\text { Orchitis } \\
\text { Lower } \\
\text { testosterone levels } \\
\text { Impaired sperm } \\
\text { quality and } \\
\text { quantity }\end{array}$ & $\begin{array}{l}\text { HHS } \\
\text { DKA } \\
\text { Mixed HHS/DKA }\end{array}$ & Adrenal infarction & $\begin{array}{l}\text { Subacute thyroiditis } \\
\text { Euthyroid sick } \\
\text { syndrome }\end{array}$ & $\begin{array}{l}\text { Pituitary } \\
\text { apoplexy }\end{array}$ & $\begin{array}{l}\text { Higher mortality } \\
\text { and morbidity } \\
\text { linked with severe } \\
\text { hyponatraemia }\end{array}$ \\
\hline $\begin{array}{l}\text { Suggestions } \\
\text { for patients } \\
\text { and } \\
\text { clinicians }\end{array}$ & $\begin{array}{l}\text { Check early } \\
\text { morning } \\
\text { testosterone level; } \\
\text { if symptoms } \\
\text { suggest hypog- } \\
\text { onadism repeat } \\
3-6 \text { months after } \\
\text { acute illness }\end{array}$ & $\begin{array}{l}\text { Education of } \\
\text { sick-day rule } \\
\text { Review of } \\
\text { diabetes } \\
\text { medication } \\
\text { including } \\
\text { metformin, } \\
\text { SGLT-2 inhibitor } \\
\text { and GLP-1 } \\
\text { agonist }\end{array}$ & $\begin{array}{l}\text { Education of } \\
\text { sick-day rule - } \\
\text { increase dose of } \\
\text { hydrocortisone } \\
\text { during acute } \\
\text { illness }\end{array}$ & $\begin{array}{l}\text { Monitor thyroid } \\
\text { function test if } \\
\text { features suggestive } \\
\text { of thyroid } \\
\text { dysfunction is } \\
\text { present }\end{array}$ & $\begin{array}{l}\text { Consider } \\
\text { checking } \\
\text { early morning } \\
\text { pituitary } \\
\text { hormonal profile } \\
\text { including cortisol }\end{array}$ & $\begin{array}{l}\text { Use of serum and } \\
\text { urine osmolality } \\
\text { and sodium } \\
\text { to establish } \\
\text { the cause of } \\
\text { hyponatraemia } \\
\text { Assess hydration } \\
\text { status }\end{array}$ \\
\hline
\end{tabular}

DKA = diabetic ketoacidosis; HHS = hyperosmolar hyperglycaemic state 


\section{Conclusion}

The effects of SARS-CoV-2 on the endocrine system are likely under-represented. Studies have shown that the gonads, thyroid, pituitary, adrenals and pancreas can all be affected by the virus as they all express the ACE2 receptor.

Severe hyperglycaemia and hyponatraemia are both independent predictors of mortality of this disease.

Guidelines have since been developed during this pandemic to help guide clinicians in managing patients with diabetes and adrenal insufficiency as they are at greater risk of complications and mortality.

Current guidelines are mostly drawn from observational cohort studies, case reports and autopsy studies. More randomised controlled trials and follow-up studies are required to assess the long-term implications of COVID-19 on the endocrine system.

\section{Key points}

> Studies have demonstrated the deleterious effects of COVID-19 on the endocrine system, ranging from pituitary apoplexy to hypogonadism.

> Society Guidelines have been developed to identify and manage patients with endocrine pathology who are diagnosed with COVID-19.

> Patients with Addison's disease and diabetes mellitus must be informed about sick-day rules.

> More follow-up research is required to determine the possible long-term effects of COVID-19 on the endocrine system.

\section{References}

1 World Health Organization. WHO Coronavirus (COVID-19) Dashboard, 2021. www.covid19.who.int/ [Accessed 05 May 2021].

2 GOV.UK. Coronavirus (COVID-19) in the UK, 2021. www.coronavirus.data.gov.uk/ [Accessed 05 May 2021].

3 Yang J, Lin S, Ji X, Guo L. Binding of SARS coronavirus to its receptor damages islets and causes acute diabetes. Acta Diabetol 2009;47:193-9.

4 Verma S, Saksena S, Sadri-Ardekani H. ACE2 receptor expression in testes: implications in coronavirus disease 2019 pathogenesis. Biol Reprod 2020;103:449-51.

5 Liu F, Long X, Zhang B, Zhang W, Chen X, Zhang Z. ACE2 expression in pancreas may cause pancreatic damage after SARS-CoV-2 infection. Clin Gastroenterol Hepatol 2020;18:2128-2130.

6 Li L, Spranger L, Soll D et al. Metabolic impact of weight loss induced reduction of adipose ACE-2 - potential implication in COVID-19 infections? Metabolism 2020;113:154401.

7 Guo W, Li M, Dong Y et al. Diabetes is a risk factor for the progression and prognosis of COVID-19. Diabetes Metab Res Rev 2020;36:e3319.

8 Schuetz P, Castro P, Shapiro NI. Diabetes and sepsis: Preclinical findings and clinical relevance. Diabetes Care 2011;34:771-8.

9 Varikasuvu SR, Varshney S, Dutt N. Markers of coagulation dysfunction and inflammation in diabetic and non-diabetic COVID-19. J Thromb Thrombolysis 2020;51:941-6.

10 Barron E, Bakhai C, Kar P et al. Associations of type 1 and type 2 diabetes with COVID-19-related mortality in England: a wholepopulation study. Lancet Diabetes Endocrinol 2020;8:813-22.

11 Holman N, Knighton P, Kar P et al. Risk factors for COVID-19related mortality in people with type 1 and type 2 diabetes in England: a population-based cohort study. Lancet Diabetes Endocrinol 2020;8:823-33.
12 Cariou B, Pichelin M, Goronflot T et al. Phenotypic characteristics and prognosis of newly diagnosed diabetes in hospitalized patients with COVID-19: results from the CORONADO study. Diabetes Res Clin Pract 2021;175:108695.

13 Pal R, Banerjee M, Yadav U, Bhattacharjee S. Clinical profile and outcomes in COVID-19 patients with diabetic ketoacidosis: a systematic review of literature. Diabetes Metab Syndr 2020;14:1563-9.

14 RECOVERY Collaborative Group; Horby P, Lim WS, Emberson JR et al. Dexamethasone in hospitalized patients with Covid-19. N Engl J Med 2021;384:693-704.

15 COncise adVice on Inpatient Diabetes (COVID:Diabetes): GUIDANCE FOR MANAGING INPATIENT HYPERGLYCAEMIA, 2020 www.diabetes.org.uk/resources-s3/public/2020-08/NEW \% 20- \% 20 COvID_Hyper_v4.1.pdf [Accessed 08 February 2021].

16 Planning sick days for your patients during COVID-19, 2020. www. professional.diabetes.org/content-page/planning-sick-days-yourpatients-during-covid-19 [Accessed 08 February 2021].

17 Enhanced sick day management - keeping clients safe during the COVID pandemic, 2021. www.diabetes.ca/resources/webinars/ enhanced-sick-day-management-keeping-clients-safe-during-thecovid-pandemic [Accessed 08 February 2021].

18 COVID-19 advice for patients, 2020. www.abcd.care/covid19/ advice-patients [Accessed 08 February 2021].

19 de Simone G. Position statement of the ESC Council on hypertension on ACE-inhibitors and angiotensin receptor blockers, 2020. www.escardio.org/Councils/Council-on-Hypertension-(CHT)/News/ position-statement-of-the-esc-council-on-hypertension-on-aceinhibitors-and-ang [Accessed 08 February 2021].

20 Diabetes Canada. FAQ about COVID-19 and diabetes. www. diabetes.ca/resources/tools-resources/faq-about-covid-19-anddiabetes [Accessed 11 August 2020.

21 Bornstein SR, Rubino F, Khunti K et al. Practical recommendations for the management of diabetes in patients with COVID-19. Lancet Diabetes Endocrinol 2020;8:546-50.

22 COVID-19 and diabetes - considerations for health care professionals, 2020. https://professional.diabetes.org/content-page/ covid-19-and-diabetes- \% E2 \% 80\% 93-considerations-health-careprofessionals [Accessed 08 February 2021].

23 Iacobellis G. COVID-19 and diabetes: can DPP4 inhibition play a role? Diabetes Res Clin Pract 2020;162:108125.

24 Khunti K, Knighton P, Zaccardi F et al. Prescription of glucose-lowering therapies and risk of COVID-19 mortality in people with type 2 diabetes: a nationwide observational study in England. Lancet Diabetes Endocrinol 2021;9:293-303.

25 Elenkov IJ. Glucocorticoids and the Th1/Th2 balance. Ann N Y Acad Sci 2004;1024:138-46.

26 Leyendecker P, Ritter S, Riou M et al. Acute adrenal infarction as an incidental $C T$ finding and a potential prognosis factor in severe SARS-CoV-2 infection: a retrospective cohort analysis on 219 patients. Eur Radiol 2021;31:895-900.

27 Hanley B, Naresh KN, Roufosse C et al. Histopathological findings and viral tropism in UK patients with severe fatal COVID-19: a post-mortem study. Lancet Microbe 2020;1:e245-e253.

28 Freire Santana M, Borba MGS, Baía-da-Silva DC et al. Case report: adrenal pathology findings in severe COVID-19: an autopsy study. Am J Trop Med Hyg 2020;103:1604-7.

29 Carosi G, Morelli V, Del Sindaco G et al. Adrenal insufficiency at the time of COVID-19: a retrospective study in patients referring to a tertiary center. J Clin Endocrinol Metab 2021;106:e1354-e1361.

30 Isidori AM, Arnaldi G, Boscaro M et al. COVID-19 infection and glucocorticoids: update from the Italian Society of Endocrinology Expert Opinion on steroid replacement in adrenal insufficiency. J Endocrinol Invest 2020;43:1141-7.

31 Arlt W, Baldeweg SE, Pearce SHS, Simpson HL. Endocrinology in the time of COVID-19: management of adrenal insufficiency. Eur ] Endocrinol 2020;183:G25-G32. 
32 Prete A, Taylor AE, Bancos I et al. Prevention of adrenal crisis: cortisol responses to major stress compared to stress dose hydrocortisone delivery. J Clin Endocrinol Metab 2020;105:2262-74.

33 Lui $\mathrm{D}$, Lee $\mathrm{C}$, Chow W et al. Thyroid dysfunction in relation to immune profile, disease status, and outcome in 191 patients with COVID-19. J Clin Endocrinol Metab 2020;106:e926-e935.

34 Scappaticcio L, Pitoia F, Esposito K, Piccardo A, Trimboli P. Impact of COVID-19 on the thyroid gland: an update. Rev Endocr Metab Disord 2020;25:1-13.

35 Lania A, Sandri M, Cellini M, Mirani M, Lavezzi E, Mazziotti G. Thyrotoxicosis in patients with COVID-19: the THYRCOV study. Eur J Endocrinol 2020;183:381-87.

36 Khoo B, Tan T, Clarke $S$ et al. Thyroid function before, during, and after COVID-19. J Clin Endocrinol Metab 2020;106:e803-e811.

37 Chen M, Zhou W, Xu W. Thyroid function analysis in 50 patients with COVID-19: a retrospective study. Thyroid 2021;31:8-11.

38 Chakraborty U, Ghosh S, Chandra A, Ray AK. Subacute thyroiditis as a presenting manifestation of COVID-19: a report of an exceedingly rare clinical entity. BMJ Case Rep 2020;13:e239953.

39 Branctella A, Ricci D, Viola N, Sgrò D, Santini F, Latrofa F. Subacute thyroiditis after Sars-CoV-2 infection. J Clin Endocrinol Metab 2020;105:2367-70.

40 Mussa B, Srivastava A, Verberne A. COVID-19 and neurological impairment: hypothalamic circuits and beyond. Viruses 2021:13:498

41 Zhou L, Zhang M, Wang J, Gao J. Sars-Cov-2: underestimated damage to nervous system. Travel Med Infect Dis 2020;36:101642.

42 Walker A, Pottinger G, Scott A, Hopkins C. Anosmia and loss of smell in the era of covid-19. BMJ 2020;370:m2808.

43 Butowt R, von Bartheld CS. Anosmia in COVID-19: underlying mechanisms and assessment of an olfactory route to brain infection. Neuroscientist 2020;1073858420956905.

44 Lou J, Movassaghi M, Gordy D. Neuropathology of COVID-19 (neuro-COVID): clinicopathological update. Free Neuropathol 2021:2:2.

45 Veldhuis J, Hammond J. Endocrine function after spontaneous infarction of the human pituitary: report, review, and reappraisal ${ }^{*}$. Endocr Rev 1980:1:100-7.

46 Solorio-Pineda S, Almendárez-Sánchez C, Tafur-Grandett A et al. Pituitary macroadenoma apoplexy in a severe acute respiratory syndrome-coronavirus-2-positive testing: causal or casual? Surg Neurol Int 2020;11:304

47 Santos C, Filho L, Santos C, Neill J, Vale H, Kurnutala L. Pituitary tumor resection in a patient with SARS-CoV-2 (COVID-19) infection. A case report and suggested airway management guidelines. Braz J Anesthesiol 2020;70:165-70.

48 Ghosh R, Roy D, Roy D et al. A rare case of SARS-CoV-2 infection associated with pituitary apoplexy without comorbidities. J Endocr Soc 2021; 5:bvaa203.

49 Chan J, Gregory K, Smithson S, Naqvi M, Mamelak A. Pituitary apoplexy associated with acute COVID-19 infection and pregnancy. Pituitary 2020;23:716-20.

50 Fleseriu M, Buchfelder M, Cetas ] et al. Pituitary society guidance: pituitary disease management and patient care recommendations during the COVID-19 pandemic - an international perspective. Pituitary 2020;23:327-37.

51 Fleseriu M, Dekkers O, Karavitaki N. Endocrinology in the time of COVID-19: management of pituitary tumours. Eur ] Endocrinol 2020;183:G17-G23.

52 Swart R, Hoorn E, Betjes M, Zietse R. Hyponatremia and inflammation: the emerging role of interleukin- 6 in osmoregulation. Nephron Physiol 2011;118:45-51.

53 Frontera ], Valdes E, Huang ] et al. Prevalence and impact of hyponatremia in patients with coronavirus disease 2019 in New York City. Crit Care Med 2020;48:e1211-e1217.

54 Ruiz-Sánchez J, Núñez-Gil I, Cuesta M et al. Prognostic impact of hyponatremia and hypernatremia in COVID-19 pneumonia. A HOPE-COVID-19 (health outcome predictive evaluation for COVID19) registry analysis. Front Endocrinol (Lausanne) 2020;11:599255.

55 Christ-Crain M, Hoorn E, Sherlock M, Thompson C, Wass ]. Endocrinology in the time of COVID-19: management of diabetes insipidus and hyponatraemia. Eur J Endocrinol 2020;183(1):G9-G15.

56 Yousaf Z, Al-Shokri S, Al-soub H, Mohamed M. COVID-19associated SIADH: a clue in the times of pandemic! Am J Physiol Endocrinol Metab 2020;318:E882-E885.

57 Ho K, Narasimhan B, Kumar A et al. Syndrome of inappropriate antidiuretic hormone as the initial presentation of COVID-19: a novel case report. Nefrología 2021:41:219-20.

58 Li D, Jin M, Bao P, Zhao W, Zhang S. Clinical characteristics and results of semen tests among men with coronavirus disease 2019 JAMA Netw Open 2020;3:e208292.

59 Guo L, Zhao S, Li W et al. Absence of SARS-CoV-2 in semen of a COVID-19 patient cohort. Andrology 2020;9:42-7.

60 Reis FM, Bouissou DR, Pereira VM, Camargos AF, Dos Reis AM, Santos RA. Angiotensin-(1-7), its receptor Mas, and the angiotensin-converting enzyme type 2 are expressed in the human ovary. Fertil Steril 2011;95:176-81.

61 Vaz-Silva J, Carneiro MM, Ferreira MC et al. The vasoactive peptide angiotensin-(1-7), its receptor mas and the angiotensin-converting enzyme type 2 are expressed in the human endometrium. Reprod Sci 2009:16:247-56.

62 Kim J, Thomsen T, Sell N, Goldsmith A. Abdominal and testicular pain: an atypical presentation of COVID-19. Am J Emerg Med 2020;38:1542.e1-1542.e3.

63 Rastrelli G, Di Stasi V, Inglese F et al. Low testosterone levels predict clinical adverse outcomes in SARS-CoV-2 pneumonia patients. Andrology 2020;9:88-98.

64 Holtmann N, Edimiris P, Andree M et al. Assessment of SARS-CoV-2 in human semen - a cohort study. Fertil Steril 2020;114:233-8.

65 de Rooij DG, Vergouwen RP. The estimation of damage to testicular cell lineages. Prog Clin Biol Res 1991;372:467-80.

Address for correspondence: Sai Man Mung, Department of Diabetes and Endocrinology, Tameside General Hospital, Fountain St, Ashton-under-Lyne OL6 9RW, UK.

Email: saiman.mung@nhs.net

Twitter: @DrYoutube7 